\title{
Study on the dilemma and solution of rural ecological environment governance
}

\author{
Hong Wang ${ }^{1, *}$, Yu Ding ${ }^{1}$ \\ ${ }^{1 *}$ Wuhan University of Science and Technology, Wuhan, China \\ ${ }^{1}$ Wuhan University of Science and Technology, Wuhan, China
}

\begin{abstract}
Since the 19th National Congress of the Communist Party of China put forward the strategy of rural revitalization, the benign governance of ecological environment is the key to rural revitalization, and also the realistic carrier of Rural Revitalization. The rural ecological environment is faced with a complex reality, characterized by scattered ecological environment management area, complex types, congenital deficiency of management conditions and lack of power in the late management and promotion. These realistic representations lead to a variety of realistic governance dilemmas. Aiming at the specific realistic ecological governance dilemmas, this paper explores the corresponding solutions to solve the problems of rural ecological environment governance, highlight the beautiful rural ecological environment state, consolidate the achievements of Rural Revitalization ecological governance, and realize the sustainable development of rural ecological environment.
\end{abstract}

\section{Introduction}

In China's rural work, the Rural Revitalization Strategy makes clear the important position of ecological environment construction in rural areas. Ecological environment protection and development has always been an important part of Rural Revitalization. With the proposal of rural revitalization, rural governance has been carried out step by step. However, the rural ecological environment governance is facing some difficulties, such as weak basic ecology in rural areas, and even historical over opening up in some areas, which leads to frequent rural ecological environment problems, Because the good ecological environment supply has the attribute of public goods, and in the perspective of traditional development mode, there is a dilemma between environment and economy. Therefore, in this dilemma, the effect of rural ecological environment governance is not ideal. How to fundamentally solve the problem of rural ecological environment governance and realize the good and livable rural environment is the original intention of this study. To explore effective governance solutions is conducive to improve the efficiency of rural ecological environment governance and realize the construction of rural ecological civilization.

\section{Realistic representation of rural ecological environment governance}

\subsection{The area of rural ecological environment management is scattered}

First of all, the agricultural environmental governance area of cultivated land in China is widely distributed, mainly concentrated in rural areas. In the agricultural governance of cultivated land area of rural ecological environment, due to the basic characteristics of wide area, it presents the decentralized representation of governance area, which directly leads to the dispersion of governance effect, It makes the governance of cultivated land agriculture in different areas have different problem orientation, and we must formulate appropriate solutions according to different problems, which increases the refinement of the work in terms of optimizing the ecological environment of rural cultivated land. Secondly, the ecological treatment of water pollution in rural areas also shows the characteristics of scattered area. Moreover, China's per capita water resources is only $1 / 4$ of the world's per capita water resources, which is a typical water shortage country. Water resource is an important ecological factor in agricultural production. In the process of industrialization and urbanization, more and more high-quality water resources are allocated to nonagricultural industries and urban and rural areas. Such decentralized governance areas make it difficult for some

\footnotetext{
* Corresponding author: wanghonglsx@163.com
} 
regions to effectively guarantee agricultural irrigation water.

\subsection{The types of rural ecological environment governance are complex}

In China's rural ecological environment governance, the types of governance need to be more complex. In the agricultural governance of cultivated land, according to the China land and resources bulletin, by the end of 2016 , the cultivated land area in China was 134956600 hectares. In 2015, due to construction occupation, disaster damage, ecological conversion of farmland, agricultural structure adjustment and other reasons, 336500 hectares of cultivated land were reduced, and 293000 hectares of cultivated land were increased through land consolidation and agricultural structure adjustment, with a net decrease of 43500 hectares in 2015. From 2009 to 2016, the area of cultivated land decreased from 135.3846 million hectares to 134.95 million hectares, a decrease of 4346 million hectares or $0.32 \%$. In such a realistic situation, industrialization, urbanization and urbanization tend to be obvious, and the governance of cultivated land and agricultural environment in rural ecological environment is more complex.

In the treatment of water pollution, China is a country with shortage of water resources, which shows the following characteristics: uneven distribution of water resources in time and space, mismatching of water and soil resources in space, coexistence of three different water shortage forms of resources, engineering and water quality, and coexistence of four phenomena of dirty water, more water, less water and muddy water. Therefore, there is a complicated situation in the water pollution treatment.

\subsection{The governance of rural ecological environment is inherently inadequate}

The congenital deficiency of rural ecological environment governance is caused by our country's traditional intensive cultivation mode and the basic congenital state of shortage of cultivated land resources. According to the China land and resources bulletin, as of the end of 2016, China's cultivated land area was 134956600 hectares. In 2015,336500 hectares of cultivated land was reduced due to construction occupation, disaster damage, ecological conversion of farmland, agricultural structure adjustment and other reasons, and 293000 hectares of cultivated land was increased through land consolidation and agricultural structure adjustment, with a net decrease of 43500 hectares in 2015. From 2009 to 2016, the cultivated land area decreased from 135.3846 million hectares to 134.95 million hectares, a decrease of 4346 million hectares or $0.32 \%$.

\subsection{The Lack of strength in the late stage of rural ecological environment management}

The rural ecological environment governance is based on the existing governance, but the existing assessment results show that some governance incentive measures adopted by the Ministry of environmental protection of China have not achieved ideal results, basically showing a weak state of governance in the later stage. In 2012, the Ministry of environmental protection officially began to evaluate the ecological performance of counties enjoying transfer payment, and the evaluation results are shown in Table 1. In Table 1, from 2012 to 2013, the implementation of the incentive measures of ecological compensation funds did not achieve good results. The continuous increase of investment did not bring about significant changes in the county ecological environment quality. On the contrary, the number of areas with improved ecological environment quality decreased from 58 to 26 , and the proportion of basically stable areas increased rapidly from $84.071 \%$ to $90.987 \%$, showing a state of constant and retrogression. However, there were some achievements in the quality of County Ecological Governance in 2015, and there was a great retrogression in 2017, which basically made it difficult to achieve a virtuous cycle of ecological governance.

\begin{tabular}{|c|c|c|c|c|}
\hline \multirow[t]{2}{*}{ File Name } & \multirow{2}{*}{\begin{tabular}{|l|l|}
\multicolumn{1}{c|}{ Number } \\
of $\quad$ counties \\
assessed
\end{tabular}} & \multicolumn{3}{|c|}{$\begin{array}{l}\text { Number of counties with changes in ecological } \\
\text { environment quality (proportion) }\end{array}$} \\
\hline & & Getting better & Variation & \begin{tabular}{|l|} 
Basically \\
unchanged
\end{tabular} \\
\hline $\begin{array}{l}\text { Bulletin on the state } \\
\text { of China's } \\
\text { environment in } 2012\end{array}$ & 452 & 58 (12.832\%) & 14 (3.097\%) & $380(84.071 \%)$ \\
\hline $\begin{array}{l}\text { Bulletin on the state } \\
\text { of China's } \\
\text { environment in } 2013\end{array}$ & 466 & 26 (5.579\%) & $16(3.433 \%)$ & 424 (90.987\%) \\
\hline $\begin{array}{l}\text { Bulletin on the state } \\
\text { of China's } \\
\text { environment in } 2014\end{array}$ & 492 & $69(14.024 \%)$ & $68(13.831 \%)$ & 355 (72.154\%) \\
\hline $\begin{array}{l}\text { Bulletin on the state } \\
\text { of China's } \\
\text { environment in } 2015\end{array}$ & 512 & 103 (20.117\%) & 65 (12.695\%) & $344(67.188 \%)$ \\
\hline $\begin{array}{l}\text { Bulletin on the state } \\
\text { of } \quad \text { China's } \\
\text { environment in } 2017\end{array}$ & 723 & 57 (7.884\%) & 81 (11.204\%) & $585(80.913 \%)$ \\
\hline $\begin{array}{l}\text { Bulletin on the state } \\
\text { of China's } \\
\text { environment in } 2018\end{array}$ & 818 & $78 \quad(9.535 \%)$ & $93(11.369 \%)$ & 647 (79.095\%) \\
\hline
\end{tabular}

Figure 1. Assessment form for ecological quality of counties enjoying transfer payment of national key ecological function areas in China from 2012 to 2017

\section{Problems to be solved in rural ecological environment management}

\subsection{Investment gap of rural ecological environment management}

There is a big gap in the investment of rural ecological environment governance, which is mainly reflected in the capital investment. In terms of capital investment, due to the dual structure of urban and rural areas in China, the thinking pattern of "attaching importance to the city and neglecting the countryside" is widespread. Instead of considering the countryside and the city in an equal framework, the countryside is placed under the city. Under this basic concept, there is an obvious gap in the investment in rural ecological environment governance. In 2017, the investment in village construction in China was 916.764 billion yuan, with an average investment intensity of 1.72 million yuan per administrative village. Among them, the municipal public facilities investment is 
252.946 billion yuan, accounting for $27.59 \%$ of the village construction investment. In the municipal public facilities, the investment in drainage and environmental sanitation was 59.967 billion yuan, accounting for $6.54 \%$ of the investment in village construction. It can be seen from the above data that there is still a big gap in the investment of rural ecological environment, especially in many specific rural basic ecological environment governance.

\subsection{Extensive governance mechanism of rural ecological environment}

The extensive governance mechanism of rural ecological environment refers to the imperfection of governance mechanism, mainly refers to the imperfection of maintenance mechanism and guarantee mechanism of ecological environment governance. The maintenance mechanism of ecological environment governance will play an effective role in the early, middle and later stages of ecological environment governance, especially in the middle and later stages.

\subsection{The rural ecological environment management technology is insufficient}

The sources of rural environmental pollution are diversified and dispersed, and it is difficult to achieve rapid rural environmental governance with existing single technology. From the perspective of pollution sources, rural pollution includes domestic pollution, agricultural production pollution and industrial production. In the past, most policies and researches focused on industrial pollution. Because of enterprises, it is relatively simple to lock the main body of pollution and the type of pollution, and the pollution is harmless

Chemical treatment is relatively easy. However, domestic pollution mainly comes from rural daily life and environment. It is also relatively easy to supervise and manage poultry raising. The hardest part is soil pollution. And the accompanying water pollution, etc, The specific performance in the rural pollution monitoring technology and treatment technology. In order to achieve agricultural pollution control, pollution control technology is urgently needed, and the role of technical control plays an important role in practice.

\subsection{Lack of supervision on rural ecological environment governance}

All kinds of work of rural environmental supervision are not strict, and even there is environmental supervision corruption. The specific performance is that there is a lack of reasonable resource investment planning in the rural ecological environment management investment; When the government pays more attention to the environment, the supervision of environmental governance is relatively strict. Once the government's environmental supervision is over, the supervision of environmental governance is relatively loose. In addition, in the rural environmental supervision, due to the characteristics of diversification and dispersion of rural pollution sources, environmental monitoring needs to fully understand the characteristics of rural soil, water and biological resources, which requires high investment and capacity of monitoring, and is difficult, which is not conducive to the follow-up ecological environmental governance.

\section{Suggestions on sustainable development methods of strengthening rural ecological environment governance}

\subsection{Strengthen the propaganda work of the concept of beautiful rural ecological environment}

In view of the rural ecological environment governance work, the most fundamental idea is to pay attention to the rural ecological environment governance. Both the basic citizens and the relevant government agencies should strengthen the concept propaganda of the beautiful ecological environment, and strengthen the understanding of the role of the benign ecological environment. On the basis of strengthening the understanding, we can fundamentally change the wrong cognition and go deep into the rural ecological environment governance work.

\subsection{Strengthen the investment of rural ecological environment management}

The realization of benign governance mainly depends on the system and funds. When strengthening the rural ecological environment governance, in order to solve the actual funding gap in all aspects of ecological governance, it is necessary to increase the investment in rural ecological environment governance, so as to provide the financial basis and guarantee for the actual effective governance.

\subsection{Provide technical support for rural ecological environment management}

Providing rural ecological technology support is an important measure to realize the benign governance of rural ecological environment. The government should increase the investment in rural environmental governance, improve the rural environmental monitoring facilities and improve the technical level of rural environmental monitoring by inclining the capital investment to the introduction and promotion of modern technology. In addition, increase the research and development of rural ecological environment treatment technology, and strengthen technical communication.

\subsection{Establishing a long-term governance mechanism of rural ecological environment}

The establishment of long-term governance mechanism of rural ecological environment mainly includes operation 
management mechanism, participation mechanism and supervision mechanism. First of all, in the operation and management mechanism section, explore and establish different mechanisms according to the important areas of rural ecological environment governance in different regions. Through the purchase of services or other ways, establish an effective operation management mechanism to ensure the normal operation of infrastructure and achieve its sustainability. Secondly, in terms of participation mechanism, the objects of governance involve farmers, enterprises, governments, scientific research institutions, etc. One of the keys to achieve the effect of rural ecological environment governance is to clearly define the boundary of the role of different stakeholders, as well as the ways of participation and cooperation, and then establish an effective participation mechanism. Finally, on the basis of the establishment of the supervision mechanism, it should be equipped with the corresponding evaluation mechanism, which is based on the premise of evaluation and guided by the purpose of supervision, and the two should cooperate with each other to finally realize the effective implementation of the supervision mechanism.

\section{References}

1. Wen Feng an. Modernization of Rural Ecological Governance: importance, governance experience and development path in the new era $[\mathrm{J}]$. Academic journal, 2020 (3).

2. Ren Yong. Issues needing attention in the modernization of ecological environment governance system and governance capacity [n]. China environment daily, November 19, 2019.

3. Yang Xue feng, Li Shuang, Wang Miaofeng. Community construction in rural environmental governance [J]. Open guide, 2019 (6): 81-84.

4. Wu er. Rural Ecological Environment Governance Dilemma and solution path under the background of Rural Revitalization -- from the perspective of social change ( J ) . Anhui Agricultural Science, 2020.48 (5): $359-262+275$.

5. Liu Jianwei. Study on the concept, necessity and Countermeasures of national ecological environment governance modernization [J]. Journal of Fujian provincial Party School of CPC, 2014 (9).

6. Zhou Xin. Public participation in the construction of modern environmental governance system [J]. Journal of Harbin Institute of Technology (SOCIAL SCIENCE EDITION), 2020 (2). 